\title{
Aboriginal Mental Healthcare in Canada: The role of alternative service delivery in transforming the provision of mental health
} services

\begin{abstract}
With growing complexity surrounding the issue of mental health, there is increased pressure for healthcare providers to engage in Alternative Service Delivery (ASD) and collaborative service delivery. Moreover, Aboriginal mental health has historically been an area of high concern and controversy, due to the high incidence of mental illness within this population. The unique social and cultural contexts that impact the type of healthcare services provided, and how these services are organized and delivered, require special consideration to be made when designing ASD models for Aboriginal mental healthcare. This paper seeks to identify current ASD initiatives being undertaken in Canada, while exploring the need for innovative and collaborative service delivery initiatives related to Aboriginal mental health, identifying current gaps and potential barriers to service delivery.
\end{abstract}

About the Authors: Danika Kowpak is a recent grad (2014) of the combined Master of Public Administration/Master of Library and Information Studies program at Dalhousie University. Danika currently works as a policy analyst at the provincial government level, and has experience working with the federal government. Danika has a Bachelor of Arts degree in Sociology from St. Francis Xavier University. This paper was originally written for Dr. Robert (Bob) Moody's Alternative Program/Service Delivery class (PUAD 6300).

Lynne Gillis is a recent grad (2014) of the Master of Public Administration program at Dalhousie University. Lynne is currently a Senior Research Analyst, and has experience working with both the public and private sectors in industries such as education, healthcare, energy, and transportation. Lynne has a Bachelor of Business degree from St. Francis Xavier University with Honours in Marketing, and has been published by the Administrative Science Association of Canada. 


\section{Introduction}

The Canadian healthcare system is often regarded as a model for patient treatment and care. As such, there is often a high level of citizen interest and engagement in the area of policy development and service delivery relating to healthcare. Mental health is one area in particular that has received growing political and media attention over the past few years (Mental Health Commission of Canada, 2012). Public consciousness of and media attention towards various mental health issues and illnesses and their impact on family members and society is being raised throughout Canada. Indeed, there has been rising interest, criticism, and debate over whether or not the healthcare system is sufficiently prepared to deal with the rise of various mental health issues. This may be due in part to the perception that the current healthcare system is failing to fully address citizens' needs in this area, highlighting the potential need to explore alternative service delivery options.

With growing complexity surrounding the issue of mental health, there is increased pressure for healthcare providers to engage in alternative service delivery (ASD) and collaborative service delivery. Moreover, Aboriginal mental health has historically been an area of high concern and controversy, due to the high incidence of mental illness within this population. The unique social and cultural contexts that impact the type of healthcare services provided, and how these services are organized and delivered, require special consideration to be made when designing ASD models for Aboriginal mental healthcare. Efforts to embrace ASD for Aboriginal health have already been undertaken in a number of areas (e.g., eHealth delivery on B.C. reserves); however, there remains a clear need for additional research if future initiatives in mental health are to be effectively designed and implemented.

The purpose of this study is to identify current ASD initiatives being undertaken in Canada to address the issue of delivering mental healthcare to Aboriginal populations. Moreover, this study explores the need for innovative and collaborative service delivery initiatives related to Aboriginal mental health, identifies specific gaps and potential barriers to ASD, and examines current best practices in relation to this form of ASD.

This paper will introduce the topics of ASD, mental health in Canada, and the Aboriginal approach to healthcare known as traditional healing. Factors that influence mental health and 
mental health service delivery will be examined. Next, eHealth will be introduced followed by an examination of a number of eHealth programs that have been undertaken in Canada. Methodology, stakeholder contributions, and limitations will be discussed before concluding with recommendations for the provision of mental health care services to Aboriginal populations in Canada.

\section{Alternative Service Delivery}

There has been an emerging focus within research literature on the use of ASD mechanisms as a means of improving government accountability. In essence, ASD entails the use of innovative yet appropriate organizational systems and arrangements to improve the overall effectiveness of program and service delivery, to improve cost-efficiencies, and/or to permit greater decision-making authority to those close to the point of service delivery (Treasury Board Secretariat, 2002).

In a democratic society, one places high importance on the concept of demonstrated accountability when evaluating program and service delivery. One of the key ways governments have chosen to demonstrate greater accountability and efficient use of public funds has been through various ASD initiatives. However, when considering any ASD initiative, government must first consider whether change will result in higher quality services and/or improved efficiencies (Lorne, 2003).

\section{Mental Health in Canada}

Many organizations and stakeholders, such as the Canadian Mental Health Association $(\mathrm{CMHA})$ and the Canadian Collaborative Mental Health Initiative (CCMHI), who deal in the area of mental health, have made concentrated efforts to bring the issues of mental health and illness to national attention. They have petitioned the government to take coordinated and collaborative action to develop and implement policy, so as to better meet the needs of communities.

To understand the complex nature of mental health service delivery, it is important to first have a broad understanding of both mental health and mental illness. Mental health broadly refers to a state of well-being that includes a balance of mental, emotional, and spiritual health. This 
balance is impacted by a number of factors, including an individual's personal relationships, home environment, community relations, work environment, and leisure activities. Generally, the focus of mental health is ensuring individuals have the appropriate coping skills to deal with normal stresses of life, to work productively, and to contribute to the community (WHO, 2007; CMHA, n.d.; MHCC, 2012). Alternatively, mental illness is a serious disturbance in thoughts, feelings, and perceptions that is severe enough to negatively affect day-to-day functioning of individuals (e.g., anxiety disorders, personality disorders). Most mental health concerns and illnesses do not have a single cause; rather, they are typically the result of a complex mix of social, economic, psychological, and biological factors (Health Canada, 2013).

\section{Aboriginal People in Canada}

As previously stated, mental health and illness has received heightened political and media attention in recent years, especially within Aboriginal communities in Canada. For the purpose of this study, the term Aboriginal Peoples refers to indigenous inhabitants. More specifically, within Canada, the term Aboriginal people includes Inuit, First Nations, and Métis. While research indicates general healthcare services to Aboriginal peoples have improved in recent years, overall, reports show that Aboriginal people continue to experience notably poorer health outcomes than non-Aboriginal Canadians (NCCAH, 2013).

\section{Aboriginal approach to healthcare: Traditional healing}

Within the past two decades we have seen an increase in the adoption of traditional Aboriginal healing practices, such as sweat lodges, talking circles, healing circles, and the medicine wheel, by government and mainstream healthcare professionals. Moreover, there has been growing attention placed on the broad benefits of these practices combined with mainstream medical treatments (Rojas \& Stubley, 2014).

At the center of Aboriginal philosophies is the concept of Spirit, which is the eternal force from which all aspects of creation evolve. Spirit is the foundation of being and consequently wellbeing, including the individual, family, and community. To nourish and honour one's Spirit there must be balance and harmony between the body, mind, and emotions. If an individual neglects 
any one of these components, an imbalance of the body will occur and this may lead to an imbalance of one's emotions and mind (Alberta Health Services, 2009; MHCC, 2012).

Within Aboriginal communities, traditional healing includes a broad and varied range of activities that include physical cures using herbal medicines and other remedies and the promotion of psychological and spiritual well-being using traditional ceremony, counseling, and the accumulated wisdom of elders. Compared to western medicine, where the goal is typically to cure disease and illness, the overall goal of traditional medicine integrated in mainstream care is to improve quality of life with an emphasis on the healing journey. Moreover, there is a more holistic approach taken to healthcare that includes the individual, family, elders, and community members (National Assembly of First Nations, 2005; Alberta Health Services, 2009; NAHO, 2002; Health Canada, 2013). Indeed, studies have shown that communitybased initiatives that take a holistic approach and combine mental health treatment, prevention, and health promotion are more effective than treatment oriented activities alone (Mental Health Commission of Canada, 2010). As such, successful approaches to health promotion, and mental health promotion in particular, should consider a more holistic approach. Actively involving Aboriginal community members in mental health service delivery may help to ensure services are responsive to local needs, which in turn, can contribute to positive mental health (Kirmayer et al., 1993; Kirmayer, Simpson \& Cargo, 2003; Williams, Guenther, \& Arnott, 2011).

\section{Factors that impact mental health \& mental health service delivery}

Although beyond the scope of this study, it is important to note that there are a variety of social determinants impacting mental health, specifically within Aboriginal communities. Socioeconomic factors, housing conditions, climate change, and cultural discontinuity are just a few of the factors that can impact mental health (Kirmayer, Brass \& Tait, 2000; Centre for Suicide Prevention, 2013; NCCAH, 2013; Rojas \& Stubley, 2014). Moreover, there are a number of factors that influence and limit a community's capacity to provide appropriate care and management of mental health and illness including, but not limited to, financial resources (e.g., high cost of program care), the state of mental health issues and illnesses (e.g. certain mental health issues require extensive, in-depth, professional care), and overall lack of caregiving and coping skills (e.g., lack of knowledge with particular mental concerns). 
Numerous studies regarding Aboriginal mental health highlight a number of issues relating to service delivery. Overall however, issues generally focus in two key areas: 1) Knowledge, Communication \& Education Gaps: Little to no effort placed on developing culturally-based options for mental health services (e.g., providing appropriate cultural competency and cultural safety training to non-Aboriginal mental health professionals) (MHCC, 2012; LHIN, 2011; Vukic, et al., 2009; Rojas \& Stubley, 2014); and 2) Service Gaps: Due to transportation and communication limitations, services in remote and northern communities in particular are often limited (Kirmayer, et al., 1993; MHCC, 2012; Vukic, et al., 2009). When evaluating these gaps, it is important to also be aware of jurisdictional issues that impact service delivery (Alberta Health Services, 2009; MHCC, 2012). While the administration and delivery of healthcare services is primarily the responsibility of the provinces, the federal government is responsible for health promotion programs and public healthcare services on First Nations reserves and within Inuit communities.

This division in governmental oversight, as well as related service gaps caused by this separation, has led to criticism by various Aboriginal groups. "Aboriginal health policy in Canada is made up of a complicated 'patchwork' of policies, legislation and agreements that delegate responsibility between the federal, provincial, municipal and Aboriginal governments in different ways in different parts of the country" (NCCAH, 2013, pg. 6). This "patchwork" has resulted in gaps and ambiguity in terms of service delivery and oversight, and creates barriers for Aboriginal peoples to gain access to appropriate healthcare services (NCCAH, 2013; Alberta Health Services, 2009).

Furthermore, while various provincial mental health services may be comprehensive, they may not be a viable option given the geographic location of specific First Nation reserves and Métis settlements. There may also be some uncertainty as to whether such provincial services are welcoming and culturally appropriate to meet the unique and varied needs of Aboriginal people (Alberta Health Services, 2009). There are numerous social, cultural, economic, and environmental differences, as well as substantial diversity in terms of values and lifestyles within Aboriginal populations that need to be considered (NCCAH, 2013). Mental healthcare services and programs considered culturally appropriate for one Aboriginal community may not necessarily be appropriate for another. As such, it would appear that successful program 
delivery lends itself to a more decentralized and customizable approach (Health Canada, 2013).

Finally, research has shown that the degree of control Aboriginal communities have over their civic life (e.g., education and healthcare), is negatively correlated with suicide rates in Canada (Lalande, 2005 as cited in Mental Health Commission of Canada, 2010). As such, given the complexities of service delivery, any successful policy implementation requires both formal and informal collaboration among provincial and federal governments and aboriginal communities.

\section{The case for eHealth}

There are many definitions for eHealth, mHealth, and telehealth. For the purpose of this paper, eHealth refers to "an integrated set of telecommunication technologies, accurate and timely information, and related process enhancements that together enable the efficient delivery of healthcare services, and incorporate the Electronic Health Record (EHR) and Telehealth" (British Columbia Ministry of Health, 2005, p. ix). As this definition suggests, telehealth is a subclass of eHealth and the two terms are often used interchangeably. Similarly, the National Institutes of Health (NIH) (n.d.) indicates that the increased use of mobile phones has the potential to improve healthcare through mobile health (mHealth). Across Canada and internationally, there are numerous cases of governments using eHealth services to assist in healthcare delivery for Aboriginal peoples. The following section highlights a few eHealth services that have been recently implemented in Canada, while Appendix $\mathrm{C}$ provides an overview of some of eHealth services that have been successfully implemented in the United States and Australia.

\section{Canadian eHealth services}

There are a number of healthcare practitioners that have been providing eHealth services across Canada for over a decade (Chandler, 2013). There is variation in project size, where individual physicians offer some projects and federal and provincial government offer others. 


\section{British Columbia}

Dr. John Pawlovich lives and works in Abbotsford, British Columbia. He also treats patients in Takla Landing, British Columbia, a remote Aboriginal community nearly 1,000 kilometres away, using a mixed method approach (Rural Coordination Centre of British Columbia [RCCbc], 2013). Pawlovich spends one week per month in Takla Landing to have face-to-face visits with his patients. With the assistance of nursing staff in Takla Landing, Pawlovich uses technology to treat the same patients remotely from his home in Abbotsford the rest of the month.

Not only does Pawlovich use traditional videoconferencing, his equipment also includes "peripheral examination tools, such as a stethoscope, an [ear, nose, and throat] camera, and a general exam camera" (RCCbc, 2013, para. 2). These tools allow the doctor to proceed as if he were in the same room as the patient (Chandler, 2013).

The success of general healthcare delivery using telehealth, "has led to further investigation about the effectiveness of telehealth in supporting specialist care" (RCCbc, 2013, para. 5). While complicated healthcare may require a larger medical centre, there is room to explore the use of telehealth in post-operative care. Further, it has been found that telehealth can lower the costs associated with healthcare by treating patients locally, rather than having the patient or physician travel (RCCbc, 2013).

There is still need to be cautious with telehealth argues Pawlovich. Indeed, telehealth, which relies only on voice communication, does not provide physicians with an opportunity to visually assess a patient. Additionally, it may be more difficult to establish an interactive dialogue between physician and patient if there is a language barrier or if the physician is unable to read non-verbal cues from the patient. Furthermore, there may be privacy and security concerns if the system does not use a secure communication link.

Due to the success of the program in Takla Landing, the British Columbia Ministry of Health announced that it would expand its telehealth project to benefit more First Nations communities in the province (Canada Health Infoway, 2013). Other provincial and territorial governments should look to the example set by British Columbia to see if a similar program can be implemented in other provinces and territories across Canada. 


\section{Ontario}

The Keewaytinook Okimakanak (KO) is an administrative council of Ojibwe-Cree Northern Chiefs in Northwestern Ontario. They represent six First Nations communities, two of which were involved in the KO pilot project (Queen's University, 2002). Additional communities were not included in the pilot project because of issues with telecommunication infrastructure (KO, 2000). The pilot telepsychiatry program was designed to overcome economic and geographic barriers to mental health services, and lower wait times to see a mental health professional. The telepsychiatry program was designed to supplement services that were already available, rather than to replace them. First Nations communities were connected to healthcare professionals using telecommunication and information technologies. In this pilot project, a psychiatrist based in Winnipeg provided a number of services, including consultation, assessment, and treatment (Queen's University, 2002).

The patients who participated in this project had a range of mental health issues that were being treated. The results of the project showed that the distance between the healthcare provider and the patient actually provided a sense of ease for the patient, as they were able to maintain a sense of anonymity and confidentiality. Further, patients said that they would likely recommend the service to others that they knew, as it responded to a specific need in the community (Queen's University, 2002).

There were a number of recommendations made based on the outcomes of the pilot project.

First, the administrative council indicated the need for ongoing negotiation with the government for the project to run smoothly. Secondly, it was indicated that due to the success of the program, it should be broadened to include more practitioners and to include services for children (Queen's University, 2002). If the telecommunications infrastructure is already in place, it would be efficient and economical to introduce telehealth services beyond telepsychiatry to the communities.

\section{Labrador}

In the isolated community of Nain, in northern Labrador, telehealth was used to connect residents of the town with a doctor in Happy Valley-Goose Bay, over 350 kilometres away, using Rosie, a Remote Presence Robotic System (CBC News, 2010; Health Canada, 2011; 
Randell, 2010). Rosie has "two-way audio and video functions that allow physicians from outside of the community to conduct appointments with patients" (Randell, 2010, para. 2). There is no permanent physician in Nain, but Rosie can help the on-site nursing staff in emergency situations by assisting in patient evaluations and being an educational resource.

Patients in Nain appreciate that they can communicate with their physician, in real time without leaving town, and the doctor has the ability to see the patient and zoom in on necessary information (CBC News, 2010). Patients were also happy and comfortable when visiting a doctor via Rosie because "their family members or interpreters could also be present in the session" (Jong, 2013, p. 169). If a patient has to fly into a larger community to meet with their physician and wants to take a family member or interpreter, there would be extra costs for transportation and lodging for the additional person. As the patients explained, Rosie can help mitigate the costs associated with visiting the doctor (Jong, 2013).

Nain only had access to Rosie for a little more than a year. However, nurses who work in the community say that such technology is a necessity due to transportation issues, such as weather or a lack of flights, which could be fatal in emergency situations (Randell, 2010). With the average trip from Nain to Happy Valley-Goose Bay taking at least three days, the addition of Rosie to the community can keep patients close to family and minimize time away from work (Randell, 2010).

While it is clear that there are benefits to using technology such as Rosie to provide healthcare to remote communities, a feasibility study and cost-benefit analysis would be needed to compare the use of a robot versus other available technologies (such as the technology used in British Columbia) as an ASD method.

\section{Methodology}

This study used a qualitative methodology based on grounded theory (Glasser \& Strauss, 1967). All interviews followed the "long interview" format outlined by McCracken (1988), and all interviews were conducted either in-person or via telephone. The interview guide (Appendix A) was designed so that biographical questions were asked first, followed by a series of 'grand tour' questions and 'planned prompts' (McCracken, 1988). Grand tour questions allow for the 
interviewee to tell their own story in their own terms. To gather additional information, planned prompts are used to gain further reflection from respondents.

The final step involved analysis of the data collected, to determine the "categories, relationships, and assumptions that informs the respondent's view of the world in general and the topic in particular" (McCracken, 1988; pg. 42).

For this study, due to time and budgetary restraints, a purposeful sample size (Lincoln \& Guba, 1985; Malterud, 2001) of six (6) was achieved, which included senior public servants, mental health care professionals, and leading academics in the field of Aboriginal health across Canada. Given the dearth amount of research that has been conducted on the effectiveness of ASD options relating to mental health services, interviews were conducted with recognized experts in the field of Aboriginal health. Each respondent was chosen on the basis of length of time in his or her respective fields, expertise in the field of Aboriginal mental health care services, and geographic location (Silverman, 2000). The purpose of this selection process was to obtain a variety of experiences from public servants, policy makers, and mental health care professionals.

\section{What the stakeholders are saying}

Due to the limited amount of information available concerning the use of ASD for mental health in aboriginal communities, interviews primarily focused on advantages and disadvantages within mental health policy and practices. Moreover, the comparative review of current mental healthcare approaches and ASD mechanisms to meet Aboriginal healthcare needs in Canada and abroad highlights a number of key benefits, challenges, and implications of telehealth and/or eHealth services.

All interviewees indicated that they have worked with Aboriginal groups, either in the past or present. The Aboriginal communities that participants have worked with span the country, from Atlantic Canada to British Columbia, and Northern Canada to Southern Ontario.

There was clear consensus amongst participants that while Aboriginal people in Canada have many health concerns, mental health issues are currently a top priority. These issues include high rates of suicide (in some communities), substance abuse and addiction, and sexual 
abuse. Participants indicated a number of underlying factors for mental health issues, including social determinants of health, socio-economic factors, and the enduring effects of intergenerational trauma or colonialism. Participants indicated the need for practitioners to get to the root cause of mental health issues and to use community-based approaches for treatment, rather than only treating the individual. While a few interviewees noted that specific mental health issues were more prominent within certain demographics (e.g., suicide rates higher among Aboriginal youth than Aboriginal people overall), there was a general agreement that mental health was an issue and a top health priority for not only Aboriginal peoples in general, but for all Canadians.

Generally, interviewees cited many of the same challenges and barriers to mental health that were noted in the literature review (e.g., service gaps in remote and rural locations, limited funding, limited awareness of available services, need for greater cultural competencies regarding approaches to traditional healing, limited collaboration between federal and provincial governments, and general stigmas of mental health). Interviewees also noted the importance of a holistic approach to service development and delivery for healthcare services that involve both levels of government and Aboriginal community members (e.g., family members, elders). More specifically, interviewees noted the importance of active engagement and shared accountability with Aboriginal peoples in service delivery development. This engagement was seen as a key factor in ensuring mental healthcare services are designed to be culturally sensitive.

Some participants were more aware of alternative service delivery mechanisms than others. Some participants indicated that traditional practices could be identified as an ASD to conventional western treatments for mental healthcare. A number of participants were aware of telepsychiatry and some were aware of pilot projects taking place across the country. These projects approached mental health service delivery in a number of different ways, including telepsychiatry consultations, capacity building, and treatment centres based on traditional practices.

Many participants noted that many Aboriginal communities across Canada are already connected to the Internet and use it for a variety of tasks, such as distance education. Participants explained that one benefit of eHealth or teleHealth is that the infrastructure is 
already in place in many of the communities. This would help keep initial service costs lower than if the infrastructure had to be established. Further, since technology is available in these communities, many individuals might already be comfortable with similar technologies. Other participants also indicated that eHealth could benefit those in rural or remote communities because they would not have to travel long distances to receive treatment. It was also indicated that eHealth may benefit Aboriginal youth who want to decide for themselves in whom to confide. They are provided many more options through eHealth than they are through face-to-face practitioners in their communities. Other participants mentioned that eHealth might help reduce or eliminate the feeling of isolation some individuals experience living in rural or remote communities across Canada. This can benefit communities in ways beyond mental health. From a service delivery perspective, some participants indicated that eHealth would allow individuals to receive treatment sooner, as wait times could be decreased by not having to wait for a practitioner to come to the community. Further, eHealth allows for the continuity of care, as healthcare practitioners can continue to treat patients on a regular basis from a distant location.

While participants indicated many benefits to eHealth services, they also identified a number of challenges that must be taken into consideration when using such services. Participants indicated that while the technology may already be in place for such services, some individuals might not have the "know-how" to use the system. If this is the case, education must be provided to make these services worthwhile to the communities. Further, it is important to get the community on board with eHealth service delivery. If they do not agree with the treatment methods provided, the services will go unused. Additionally, some participants noted that it is harder to understand context through technology, as practitioners may not be seeing the same social or physical cues that they would see during an in-person session. Practitioners may also have a more difficult time gaining the trust of an individual or the community if they do not physically visit the community to gain a better understanding of the people, culture, and traditions. Participants also indicated that technology might be leading to children losing human connection with others. As was mentioned throughout the interviews, a sense of belongingness and connectedness to the community is important. eHealth may actually perpetuate a sense of disconnect from the community. Participants also indicated that there might be challenges in terms of coordinating the services for communities in rural and remote 
parts of the country. Finally, some participants argued that while there is merit for eHealth being used as a treatment method, there needs to be safeguards against it being the entire treatment. A more integrated approach would better serve the communities.

Participants indicated that there is potential for eHealth services to work for all segments of the Aboriginal communities, but that some may adopt the method more easily than others. Many participants suggested that Aboriginal youth are already engaged with social media and eHealth could be seen as an extension of their current activities on the Internet. On the other hand, there may be challenges getting the Elders to use the services, either because they are unaware of what the technology can offer or because they prefer to see a healthcare practitioner in person. Further, older populations may require more education on how to use the technology once they are made aware of the services that can be provided electronically and patients who are unable to travel easily may benefit from these services. Finally, it is important to note that some remote communities may not have the technological infrastructure to support such services (e.g., community members may not have personal access to requisite technologies). Participants cautioned, however, against eHealth services being used for highrisk patients, as it may be harder to respond to emergency situations.

\section{Limitations}

There are limitations to keep in mind when considering these findings and recommendations. First, while qualitative research allows for a better understanding of the benefits and challenges of using ASD mechanisms, such as telehealth and eHealth, for mental health services for Aboriginal people, it does not allow for any type of measurement of the findings. As such, this study may only be looked upon as an 'insight' into the use of ASD in this specific field of healthcare and is not generalizable to ASD applications in general. Second, the six expert interviews is a smaller sample than McCracken (1989) suggests is necessary and all were recruited from a non-probability sample.

Third, all experts were chosen from Canada, three being from Nova Scotia. Given that healthcare is under provincial jurisdiction and the percentage of the total Aboriginal population within each province and territory varies significantly, there may be significant differences between provinces and between Aboriginal groups within the province that may warrant further 
investigation (Appendix B). Perhaps in provinces with higher proportions of Aboriginal people or in provinces where a greater number of reserves are in rural or remote areas, there may be different perceived benefits and challenges of ASD. Moreover, while we looked at ASD mechanisms being used internationally, no interviews were conducted with experts outside of Canada. Therefore, responses must be interpreted within the Canadian context.

Finally, this study only dealt with healthcare administrators and healthcare practitioners whose work, while solely and significantly focused on healthcare services for Aboriginal Peoples, was not solely done from an on-reserve office location. Moreover, this study did not include patients of Aboriginal mental healthcare services. Patients may be able to offer additional valuable insights into the benefits and challenges of using these ASD mechanisms.

\section{Recommendations}

Based on the literature review and interviews we have identified five recommendations to be considered when developing and implementing an ASD approach to mental health services for Aboriginal peoples.

1. Develop a two-eyed approach, whereby both traditional and western practices are incorporated into service delivery: There is a clear need for culturally based options for mental health services and a need for cultural competency training for service providers. To be most effective, any ASD initiative should include both approaches so that the individual and not the illness is treated.

2. Conduct a cost-benefit analysis to determine the most suitable ASD option: Given the jurisdictional challenges related to Aboriginal healthcare, and rising healthcare costs in general, it is important to realize that any evaluation related to such an ASD initiative will be a complicated and perhaps controversial process. There are inherent difficulties to cost-benefit analyses on any new initiative. Costs related to time and other organizational resources are often difficult to account for. It is also difficult to quantify the short-term and long-term benefits that are consequently acquired. However, such analysis will be essential in determining which delivery method is most appropriate for a particular community. 


\section{Prior to development of any ASD mechanism consult with Aboriginal community}

members to ensure the program meets community needs and is culturally sensitive: ASD mechanisms must reflect the specific and unique needs of the community, rather than the community conforming to the delivery method. As previously mentioned, no two Aboriginal communities in Canada should be assumed to have the same needs in relation to mental health. As such, service delivery options must be appropriately adaptable.

4. Ensure technical infrastructure and training is in place: While there have been significant technological improvements over the past decade, it is important to note there are still barriers to accessing the Internet. Fewer than 50 percent of all Aboriginal peoples have access to high-speed Internet. A feasibility assessment would need to be conducted on any initiative such as eHealth prior to development (NAHO, 2008).

\section{A more extensive qualitative and quantitative study should be conducted: The} goal of this research was to explore the benefits and challenges to using ASD options in mental healthcare for Aboriginal peoples. Since research on this relationship is relatively new, there are areas that could be examined in greater detail. It became apparent during the course of the research that the mental health service delivery is a highly complex and sensitive issue, involving a large number of key stakeholders within government, Aboriginal communities, non-profit organizations, and special interest groups. The results of this study raise several questions, as mentioned earlier, which may be addressed in future research.

\section{Conclusion}

As previously mentioned, there is little research done concerning the use of ASD for Aboriginal mental healthcare. With that being said, it is the hope that the findings from this study may bring insight into the previously under explored, and sometimes questionable, use of ASD mechanisms to meet the mental healthcare needs of Aboriginal peoples, by examining both the potential benefits and challenges of initiatives such as telehealth and eHealth. To be most effective, ASD mechanisms must appropriately incorporate both traditional Aboriginal and western practices, be cost-effective given the specific socio-demographic realities of the 
particular community in question, and have the necessary technical infrastructure and training in place to allow for programs to be successfully implemented.

While research appears to support the idea that the potential benefits of ASD outweigh the challenges, further research into this area is required before implementing these services to fully understand the specific intricacies, benefits, and challenges to using ASD options in providing mental healthcare to Aboriginal peoples. This is particularly important given the sensitive nature of the subject matter and growing public pressure for government to deliver healthcare services that produce measurable improvements within the system in the most cost-effective manner. Moreover, given rapid improvements within the technological sector, it will be essential that these ASD mechanisms be regularly evaluated to ensure that mental health services are delivered in the most beneficial and cost-effective manner possible. 


\section{References}

Alberta Health Services. (2009). Aboriginal mental health: A framework for Alberta. Retrieved from: http://www.albertahealthservices.ca/MentalHealthWellness/hi-mhw-aboriginalframework.pdf

Assembly of First Nations. (2005). First Nations action plan for non-insured health benefits.

Retrieved from: http://64.26.129.156/cmslib/general/NIHB\%20Action\% 20Plan_Fe.pdf

Australian Bureau of Statistics. (2012). 2075.0 - Census of population and housing -counts of Aboriginal and Torres Strait Islander Australians, 2011. Retrieved from http://www.abs.gov.au/ausstats/abs@.nsf/Lookup/2075.0main+features32011

Australian Indigenous HealthInfoNet. (2013). HITnet kiosk [12 audiovisual healthmessages] (2010). Retrieved from http://www.healthinfonet.ecu.edu.au/keyresources/promotion-resources?lid=24385

BC Partners for Mental Health and Addictions Information. (2014). The facts. Retrieved from www.heretohelp.bc.ca/visions/aboriginal-people-vol5/aboriginal-mental-health-thestatistical-reality

British Columbia Ministry of Health. (2005). eHealth strategic framework. Retrieved from http://www.health.gov.bc.ca/library/publications/year/2005/ehealth_ framework.pdf

Byrne, M. (2001). Grounded theory as a qualitative research methodology. Association of Operating Room Nurses Journal, 73(6),1155-1156. Retrieved from ProQuest.

CBC News. (2010, July 9). Robot helps connect Labrador patients, doctors. Retrieved from http://www.cbc.ca/news/canada/newfoundland-labrador/robot helps-connectlabrador-patients-doctors-1.975104

Canada Health Infoway. (2013). Telehealth expansion project to benefit BC First Nations. Retrieved from https://www.infoway-inforoute.ca/index.php/news-media/2013-newsreleases/telehealth-expansion-project-to-benefit-bc-first-nations

Canadian Mental Health Association (CMHA). (n.d.). Meaning of mental health. Retrieved from http://www.cmha.ca/mental_health/meaning-of-mental-health/

Canadian Mental Health Association (CMHA). (n.d.). Understanding mental illness. Retrieved from http://www.cmha.ca/mental-health/understanding-mental-illness/

Carrier Sekani Family Services. (2011). Carrier Sekani Nations. Retrieved from http://www.csfs.org/files/carrier-sekani-nations.php 
Centre for Rural \& Remote Mental Health. (2009). Building bridges: Learning from the experts. Retrieved from http://www.acrrmh.com.au/assets/Uploads/Building-BridgesLearning-From-the-Experts.pdf

Centre for Suicide Prevention. (2013). Aboriginal, Inuit, First Nations \& Métis suicideprevention resource toolkit. Retrieved from:

https://suicideinfo.ca/LinkClick.aspx?fileticket=MVlyGo2V4YY\%3D\&tabid=563

Chandler, A. (2013). The future of health care. Best Health Magazine. Retrieved from http://rchfoundation.com/wp-content/uploads/Best-Health-Magazine-Mar-Apr2013.pdf

Dunn, W. (2012). Public Policy Analysis (3rd ed.). Boston: Pearson Education.

Gibson, K.L., Coulson, H., Miles, R., Kakekakekung, C., Daniels, E., \& O'Donnell, S. (2011). Conversations on telemental health: listening to remote and rural First Nations communities. Rural and Remote Health, 11, 1-19. Retrieved from http://www.rrh.org.au

Glaser, B.G. \& Strauss, A.L. (1967). The discovery of grounded theory: Strategies for qualitative research. Chicago: Aldine.

Government of Alberta. (2014). First Nations telehealth portal. Retrieved from http://www.firstnationsth.ca/

Government of Manitoba. (2014). MBTelehealth. Retrieved from http://mbtelehealth.ca/

Government of Yukon. (2009). Yukon telehealth network (YTN). Retrieved from http://www.hss.gov.yk.ca/telehealth.php

Health Canada. (2014). A tool to help people from far away: The IIU telehealth network. Retrieved from http://www.apps.hc-sc.gc.ca/hcs-sss/phctffassp.nsf/WebFactSheet/0063?OpenDocument\&lang=eng\&

Health Canada. (2011). Atlantic tele-robotic. Retrieved from http://www.hc-sc.gc.ca/ahcasc/media/video/atlant-telerobot-eng.php

Health Canada. (2012). First Nations and Inuit health strategic plan: A shared path to improved health. Retrieved from: http://www.hc-sc.gc.ca/fniah-spnia/pubs/strat-plan2012/summary-sommaire-eng.php

Health Canada. (2013). National Aboriginal youth suicide prevention strategy: Program framework. Retrieved from http://sciencessociales.uottawa.ca/crecs/eng/ documents/EvaluationFramework-NAYSPS-07-10-26.pdf 
Health Interactive Technology Network. (2010). HITnet kiosk data report. Retrieved from http://www.hitnet.com.au/files/KioskDataReport.pdf

Health Interactive Technology Network. (2011). Bringing culturally relevant health information to disadvantaged Australians. Retrieved from http://www.hitnet.com.au/files/NTChronicDiseasesArticle.pdf

Hunter Institute of Mental Health. (2012). Aboriginal and Torres Strait Islander Australians. Retrieved from http://www.mindframe-media.info/for-mental-health-and-suicideprevention/talking-to-media-about-suicide/priority-population-groups/aboriginal-andtorres-strait-islander-australians

Jong, M. (2013). Impact of robotic telemedicine in a remote community in Canada.Proceedings of the Fifth International Conference on eHealth, Telemedicine, and Social Medicine, 168-171. Retrieved from thinkmind.org http://thinkmind.org/index.php?view=article\&articleid=etelemed_2013_10_10_40008

Keewaytinook Okimakanak. (2000). Telepsychiatry pilot project. Retrieved from $\mathrm{ftp}: / /$ storage.knet.ca/pub/cdrom/Websites/health/telepsychiatry.html

Kirmayer, L.J., Brass, G.M. \& Tait, C.L. (2000). The mental health of Aboriginal peoples: Transformations of identity and community. Canadian Journal of Psychiatry, 45(7), 607-616. Retrieved from PsycINFO.

Kirmayer, L.J., Gill, K., Fletcher, C., Ternar, Y., Boothroyd, L., Quesney, C., Smith, A., Ferrara, N. \& Hayton, B. (1993). Emerging trends in research on mental health among Canadian Aboriginal peoples: A report prepared for the Royal Commission on Aboriginal peoples. Retrieved from: https://www.mcgill.ca/files/tcpsych/Report2.pdf

Kirmayer, L., Simpson, C. \& Cargo, M. (2003). Healing traditions: Culture, community and mental health promotion with Canadian Aboriginal peoples. Australasian Psychiatry, 11(1),15-23. doi: 10.1046/j.1038-5282.2003.02010.x

Kumar, S. (2003). Why do general practitioners prescribe antibiotics for sore throat? Grounded theory interview study. British Medical Journal, 326(7381), 138-141. doi: 10.1136/bmj.326.7381.138

Lincoln, Y. \& Guba, E. (1985). Naturalistic Inquiry. Thousand Oaks: Sage.

Lips, A, O’Neill, R. \& Eppel, E. (2011). Cross-agency collaboration in New Zealand: An empirical study of information sharing practices, enablers and barriers in managing for shared social outcomes. International Journal of Public Administration, 34(4), 255-266. doi: 10.1080/01900692.2010.533571

Local Health Integration Network. (2011). North East Aboriginal / First Nation and Métis mental health and additions framework. Retrieved from: http://www.nelhin.on.ca/home.aspx 
Malterud, K. (2001). Qualitative Research: Standards, challenges, and guidelines. The Lancet, 358(9280), 483-488. doi: 10.1016/S0140-6736(01)05627-6

McCracken, G. (1988). The Long Interview. London: SAGE Publications.

Mental Health and Addictions Strategy Advisory Committee. (2012). Come together: Report and recommendations of the mental health and addictions strategy advisory committee. Retrieved from: http://novascotia.ca/dhw/mental-health/reports/ComeTogather-Summary.pdf

Mental Health Commission of Canada. (2012). Changing directions, changing lives: The mental health strategy for Canada. Retrieved from: http://strategy.mentalhealth commission.ca/pdf/strategy-text-en.pdf

Mood Disorders Society of Canada. (2009). Quick facts: Mental illness and addiction in Canada. Retrieved from: http://www.mooddisorderscanada.ca/page/quick-facts

Muttitt, S., Vigneault, R., \& Loewen, L. (2004). Integrating telehealth into Aboriginal healthcare: The Canadian experience. International Journal of Circumpolar Health, 63(4), 401414. Retrieved from DOAJ.doi: http://dx.doi.org/10.3402/ijch.v63i4.17757

National Aboriginal Health Organization. (2003). Ways of knowing: A framework for health research. Retrieved from http://www.naho.ca/documents/naho/french/pdf/research_waysof.pdf

National Aboriginal Health Organization. (2008). Internet connectivity among aboriginal communities in Canada. Retrieved from

http://www.naho.ca/documents/naho/english/2008_Aboriginal_connectivity_rates.pdf

National Collaborating Centre for Aboriginal Health. (2013). An overview of Aboriginal health in Canada. Retrieved form http://www.nccahccnsa.ca/Publications/Lists/Publications/Attachments/101/abororiginal_health_web.p df

National Institutes of Health. (n.d.). mHealth: Mobile health technologies. Retrieved from http://obssr.od.nih.gov/scientific_areas/methodology/mhealth/

Ontario's Comprehensive Mental Health \& Addictions Strategy. (2011). Open minds, healthy minds. Retrieved form http://www.health.gov.on.ca/en/common/ministry/publications/reports/mental_health 2011/mentalhealth_rep2011.pdf

Pal, L. (2010). Beyond Policy Analysis: Public Issue Management in Turbulent Times. Ottawa: Nelson Education Ltd. 
Queen's University. (2002). Evaluation of the Keewaytinook Okimakanak telepsychiatry pilot project. Retrieved from http://knet.ca/documents/KO-Telepsychiatry-Report-2002-1221.pdf

Randell, A. (2010, July 15). A robot called Rosie. The Labradorian. Retrieved from http://www.thelabradorian.ca/News/2010-07-15/article-1569214/A-robot-calledRosie/1

Rojas, M. \& Stubley, T. (2014). Integrating mainstream mental health approaches and traditional Aboriginal healing practices: A literature review. Advances in Social Sciences Research Journal, 1(1), 22-43. doi: 10.14738/assrj.11.64

Rural Coordination Centre of British Columbia. (2013). Pioneering telehealth for BC's rural and remote First Nations communities. Retrieved from http://rccbc.ca/enews/2013/06/pioneering-telehealth-for-bcs-rural-and-remote-firstnations-communities/

Scott, J.E. (2000). Facilitating interorganizational learning with information technology. Journal of Management Information Systems, 17(2), 81-113. Retrieved from ABI/Inform.

Shore, J.H., Bloom, J.D., Manson, S.M., \& Whitener, R.J. (2008). Telepsychiatry with rural American Indians: Issues in civil commitments. Behavioral Sciences and the Law, 26(3), 287-300. doi: 10.1002/bsl/813

Shore, J.H., Brooks, E., Anderson, H., Bair, B., Dailey, N., Kaufmann, L.J., \& Manson, S. (2012). Characteristics of telemental health service use by American Indian veterans. Psychiatric Services, 63(2), 179-181. doi: 10.1176/appi.ps.201100098

Silverman, D. (2000). Doing Qualitative Research. London: SAGE Publications.

Social and Emotional Wellbeing and Mental Health Services in Aboriginal Australia.(n.d.). Support services for those with a mental illness or suicide risk. Retrieved from http://www.sewbmh.org.au/page/3672

Star, S. L. (1998). Grounded classification: Grounded theory and faceted classification. Library Trends, 47(2), 218-232. Retrieved from EBSCOhost.

Statistics Canada. (2011). Aboriginal peoples in Canada: First Nations, Métis and Inuit. Retrieved from: http://www12.statcan.gc.ca/nhs-enm/2011/as-sa/99-011-x/99-011x2011001-eng.cfm

Strauss, A. \& Corbin, J (Eds.). (1997). Grounded theory in practice. London: SAGE Publications.

Treasury Board Secretariat. (2002). Policy on Alternative Service Delivery. Retrieved from: http://www.tbs-sct.gc.ca/pubs_pol/opepubs/tb_b4/asd-dmps01-eng.asp 
Vukic, A., Rudderham, S., \& Misener, R.M. (2009). A community partnership to explore mental health services in First Nations communities in Nova Scotia. Canadian Journal of Public Health, 100(6), 432-435. Retrieved from ProQuest.

Williams, E., Guenther, J., \& Arnott, A. (2011). Traditional healing: a literature review. Working paper series 2: Evaluation and policy. No. 2, Covaluator Network. Retrieved from: http://www.covaluator.net/docs/S2.2_traditional_healing_lit_review.pdf.

World Health Organization. (2007). What is mental health? Retrieved from http://www.who.int/features/qa/62/en/

Wright, B. \& Barling, J. (1998). The Executioners' song: Listening to Downsizers reflect on their experiences. Canadian Journal of Administrative Sciences, 15(4), 339-355. doi: 10.1111/j.1936-4490.1998.tb00176.x

Yurkovich, E.E., Clairmont, J., \& Grandbois, D. (2002). Mental health care providers'perception of giving culturally responsive care to American Indians. Perspectives in Psychiatric Care, 38(4), 147-156. doi: 10.1111/j.1744-6163.2002.tb01565.x 


\section{Appendix A}

Expert Interview Script

Participant Profile:

Name:

Title:

Organization:

Date / Time of Interview:

\section{Introduction:}

Thank you for taking the time to help us with our study. Our discussion should take no longer than 60 minutes. As mentioned in our email, the purpose of our discussion today is to discuss mental health services among aboriginal populations.

[Interviewer Note: remind participant of consent form either by confirming receipt or by confirming that they have filled out the form and will be mailing the consent form in]

With your approval we would like to audio record today's discussion for reporting purposes only, so we do not have to take a lot of detailed notes. We will be the only ones that will be listening to the recording. Everything you say today is completely anonymous and confidential. Your comments will be combined with those from other experts that we interview, as part of a detailed study report. Do you have any questions before we begin? 


\section{Interview Guide:}

Note to Interviewer: This script is simply meant to act as a guide for the interview; the actual interview will likely deviate from this script.

1. Do you currently work with any Aboriginal groups [or have you done work with Aboriginal groups in the past]?

2. What Aboriginal communities have you done work with [or have you done work with in the past]?

3. What would you consider to be the current top health priorities for Aboriginal people in Canada? [If Mental Services is not mentioned, probe for additional health priorities by asking if there is "anything else" they believe is a current health priority]

Note to Interviewer: If participant does not feel that mental health issues are a current health priority thank participant for their time and input and terminate interview.

\section{Mental Health Overview Within Aboriginal Communities}

4. In your opinion, are there key demographics within Aboriginal communities that are most affected by mental health conditions (e.g., women, children/youth, Elders, people with disabilities, etc.)?

5. What are some of the key challenges and/or barriers to address mental health in Aboriginal communities? [If not mentioned: Probe about challenges and/or barriers regarding access issues]

6. How do community attitudes towards mental health impact service delivery? 


\section{Current Mental Health Services}

7. Are you aware of specific activities being done in Aboriginal communities to address mental health issues?

8. What, if any, activities are working well to address these issues? What has been the impact of these activities? In your opinion, why have these activities been successful?

9. Are there any 'gaps' in mental health services for Aboriginal communities? [If so, what are the specific gaps?]

10. In your opinion, how can service delivery to Aboriginal communities be improved?

11. Do you believe that mental health services should be modified to fit the unique social and cultural differences of Aboriginal communities? [If yes: How so? Could you please provide an example?]

\section{Alternative Service Delivery \& Aboriginal Mental Health Services}

12. Are you aware of any alternative service delivery mechanisms being used to address mental health issues [If required, provide a brief description of ASD]? [If not mentioned: are you aware of the use of eHealth and $m$ Health in delivering health services in Aboriginal communities? If no, provide brief overview.]

13. [If aware of eHealth and mHealth] What do you perceive to be the core benefits of eHealth and mHealth? What do you perceive to be the core challenges of using such service?

14. Do you believe that eHealth and mHealth are more appropriate for certain segments of Aboriginal communities than others? 
15. Do you have any additional insights into this topic area that you would like to share?

\section{Conclusion:}

That concludes our questions. On behalf of Lynne and I, the School of Public Administration at Dalhousie, we would like to thank you for your time and input.

[Interviewer Note: Ask participant if they would like to receive a copy of the final report. If so, get email/mail address and let them know approximately when the report will be available. Finally, ask if the participant has any suggestions as to other potential interviewees he/she believes would be beneficial to include in our study.] 


\section{Appendix B}

Percentage of all First Nations People in Each Province / Territory

\begin{tabular}{|cc|}
\hline & $\begin{array}{c}\% \text { of all First } \\
\text { Nations People in } \\
\text { Province / Territory }\end{array}$ \\
\hline Ontario & $21.5 \%$ \\
\hline British Columbia & $16.6 \%$ \\
\hline Alberta & $15.8 \%$ \\
\hline Manitoba & $14.0 \%$ \\
\hline Saskatchewan & $11.3 \%$ \\
\hline Quebec & $10.1 \%$ \\
\hline Newfoundland \& Labrador & $2.6 \%$ \\
\hline Nova Scotia & $2.4 \%$ \\
\hline Nunavut & $2.0 \%$ \\
\hline New Brunswick & $1.6 \%$ \\
\hline Northwest Territories & $1.5 \%$ \\
\hline Yukon & $0.6 \%$ \\
\hline Prince Edward Island & $0.2 \%$ \\
\hline
\end{tabular}

(Statistics Canada, 2011) 


\section{Appendix C}

Overview of Selected eHealth Services Being Implemented Internationally to Address the Healthcare Needs of Aboriginal Peoples

\section{The United States}

In the United States, eHealth services, particularly interactive videoconferencing (also called telepsychiatry), are being used to provide treatment to rural American Indians and to American Indian veterans (Shore, Bloom, Manson, \& Whitener, 2008; Shore et al., 2012). Close to 2.5 million Americans identify as American Indian or Alaska Native, belonging to one of over 560 federally recognized tribes (Shore et al, 2008). The use of telepsychiatry can improve "both the access and quality of care available to rural American Indian reservations" (Shore et al., 2008, p. 289).

Shore et al. (2012) indicate that "American Indian and Alaska Native veterans have high rates of substance use disorders and posttraumatic stress disorder (PTSD), have the greatest proportional representation of all males in the military, and have the highest proportion of rural residence of any veteran group" (2012, p. 179). Shore et al. (2012) argue that the United States Department of Veterans Affairs faces an increased level of difficulty to get proper mental health services to these locations and to find culturally competent physicians. It has been found that telepsychiatry services have provided satisfactory results for patients in rural areas, but there were concerns over the cost and feasibility of these services for veterans (Shore et al., 2012).

To address the needs of the veterans, the University of Colorado partnered with Veterans Affairs and the Indian Health Service. Many of the needs were tackled through the American Indian and Alaska Native Programs (AIANP), run by the medical school at the University of Colorado (Shore et al, 2008). American Indian veterans were treated in their home communities, by professionals in Denver, via teleconferencing (Shore et al., 2012). Veterans were most commonly treated for PTSD, but in many circumstances, there were multiple diagnoses - generally three to four diagnoses per patient (Shore et al., 2012). Shore et al. 
(2012) found that after beginning teleHealth services, the use of other health services and prescription medication by American Indian veterans increased significantly. Also, lower rates of hospitalization, likely due to better assessment, were observed.

A major challenge identified by Shore et al. (2008) is the issue of jurisdiction - do all States have the same laws or require the same credentials? Are reserves self-governing? Can a psychiatrist provide service via videoconference across state lines? Further, Shore et al. (2008) indicated that "privacy, security, confidentiality, informed consent, and professional liability" are all issues that must be taken into consideration when providing mental health services to American Indian veterans via videoconferencing (Shore et al., 2008, p. 289). It is also important for practitioners to "[establish] emergency protocols for telepsychiatry clinics" (Shore et al., 2008, p. 296), as it is more difficult to reach out to someone in crisis over the Internet. These are all questions that need to be considered before providing mental health services to American Indian veterans on reserves or in remote communities.

\section{Australia}

According to the Australian Bureau of Statistics, there were 548,370 Aboriginal and/or Torres Strait Islanders living in Australia in 2011 (Australian Bureau of Statistics [ABS], 2012, para. 1). Aboriginal and Torres Strait Islander people have a younger median age than the general Australian population (21 years old versus 37 years old), and have a much shorter life expectancy (Hunter Institute of Mental Health [HIMH], 2012). Statistics related to Aboriginal and Torres Strait Islander rates of suicide should be used cautiously, as they may underestimate reality $(\mathrm{HIMH}, 2012)$. For the period of 2001-2010, the rate of Aboriginal and Torres Strait Islander suicide was slightly more than double that of the non-Aboriginal population (21.4 per 100,000 compared to 10.3 per 100,000) (HIMH, 2012).

The government of Australia identified the need to provide general health information and specific mental health information to disadvantaged Australians, including Aboriginal and Torres Strait Islander people in rural or remote parts of the country (Social and Emotional Wellbeing and Mental Health Services in Aboriginal Australia [SEWBMH], n.d.; Health Interactive Technology Network [HITnet], 2014). 
With funding from the Australian Government Department of Health and Ageing, Health Interactive Technology (HITnet) installed touchscreen kiosks in remote communities to share health information with Aboriginal and Torres Strait Islander people across the country (SEWBMH, n.d.). Further, "the information provided on the kiosks is managed and kept up-todate by a head office, which also collects data about who is accessing the information and which information is being accessed" (SEWBMH, n.d., para. 10).

Using the kiosks, a mental health workshop called Frame of Mind is delivered to Aboriginal and Torres Strait Islander peoples in Cape York, Queensland, Australia. According to the SEWBMH, the "aim is to remove the stigma associated with mental illness by raising the awareness of generalist non-clinical health staff and other interested community members" (n.d., para. 11). The information provided is part of a first aid course on mental health accredited by the Australian government (SEWBMH, n.d.).

As of 2010, HITnet had 30 kiosks available for use in Queensland, including 11 in Cape York and one on the Torres Strait Islands (HITnet, 2010). Crucial to the success of these kiosks, the content is culturally appropriate, interactive, visual (videos, games, etc.), and appropriate for those with low levels of literacy, as well as those not familiar with technology (Australian Indigenous HealthInfoNet, 2013). The information provided about mental health was based on a community engagement model and was also made available as an interactive DVD to be distributed in high-risk areas (HITnet, 2010; HITnet, 2011).

Since its introduction of four kiosks in Cape York, in 2005, the Frame of Mind program has shown success and has expanded from a pilot project to a program delivered in rural and remote areas across Australia (Centre for Rural \& Remote Mental Health [CRRMH], 2009; SEWBMH, n.d.). As of 2011, the program has expanded "to the current network of 70 kiosks in Queensland, Western Australia, South Australia and the Northern Territory" (HITnet, 2011, p.16). This rapid and broad expansion indicates that individuals have responded well to this form of service delivery. The feasibility of such a program in remote Canadian communities should be studied. 